\title{
Are the Circulating Levels of Copeptin and Fibronectin Dysregulated in Preeclamptic South African Black Women?
}

\author{
Kayshia Deepnarain $^{1}{ }^{\circledR}$, Thajasvarie Naicker ${ }^{\circledR}{ }^{\circledR}$, Sapna Ramdin $^{1}{ }^{\circledR}$, Poovendhree Reddy $^{(}{ }^{\circledR}, N^{2}$ lini \\ Govender $^{1 * \mathbb{D}}$
}

\begin{abstract}
Objectives: To establish the circulating levels of copeptin and fibronectin in normal and preeclamptic Black South African pregnant females.

Materials and Methods: Serum copeptin and fibronectin levels were measured in preeclamptic and normotensive women via enzyme-linked immunosorbent assays. Data are presented as medians and interquartile ranges. Spearman's chi-square test was used to evaluate bivariate associations between analytes and clinical variables.

Results: Fibronectin levels were downregulated in preeclampsia (PE) compared to the control group $(P<0.05)$. Copeptin levels displayed an upward trend in PE compared to the normotensive group. Blood pressure (systolic and diastolic) was significantly different between preeclamptic and normotensive women $(P<0.005)$. In the preeclamptic group, gestational age was negatively correlated with systolic blood pressure $(r=-0.8, P<0.05)$. In addition, diastolic blood pressure was negatively correlated with maternal weight $(r=-0.58, P<0.05)$ and gestational age $(r=-0.76, P<0.05)$ in the preeclamptic group. Eventually, a positive correlation was noted between diastolic blood pressure and systolic blood pressure $(r=0.65, P<0.05)$ in PE.

Conclusions: This was the first South African study to measure copeptin and fibronectin in pregnant women. The findings demonstrated a dysregulation in copeptin and fibronectin serum levels between the normotensive pregnant and preeclamptic groups, suggesting a potential diagnostic indicator of PE development.

Keywords: Pregnancy, Preeclampsia, Copeptin, Fibronectin
\end{abstract}

\section{Introduction}

Global variation in the frequency of preeclampsia (PE) projects a 7 times higher prevalence in developing compared to developed countries (1). The cause of PE is linked to defective trophoblast invasion occurring in early pregnancy (2). The use of angiogenic biomarkers combined with standard care can predict PE development according to low or moderate and elevated risk (3), however, its implementation in low resourced countries is constrained by high costs. Despite the clinical significance of the soluble FMS-like tyrosine kinase 1/placental growth factor (PlGF) ratio, its imbalance is usually observed mid-gestation prior to the clinical onset of symptoms (4). The onset of the non-physiological remodeling of the uterine artery during the first trimester substantiates the investigation of the vascular regulator, arginine vasopressin (AVP) as a potential link in the pathogenic mechanism (5).

AVP is a multifunctional regulatory hormone and a critical osmotic and blood pressure regulator. Copeptin, as a surrogate biomarker of AVP, is secreted in response to hemodynamic or osmotic stimuli and has a pronounced stability in serum and plasma supporting its use as a measure of circulating AVP levels (6). In contrast, fibronectin is produced by endothelial cells and exists as either soluble plasma fibronectin or insoluble cellular fibronectin (7). Elevated fibronectin levels may signify endothelial damage (8). It is likely that the levels of circulating fibronectin are elevated in PE since endothelial lesions are pathognomonic of PE (9). Although the circulating levels of both copeptin and fibronectin are widely reported in various populations, there are no data available within South Africa. Thus, this study aimed to establish the circulating levels of copeptin and fibronectin in both normal and preeclamptic South African Black pregnant women.

\section{Materials and Methods}

Study Population

Purposive sampling was used to recruit 32 Black African pregnant women attending a large primary healthcare centre in KwaZulu-Natal, South Africa. This included 
both early-onset preeclamptic $(n=16)$ and normotensive women $(n=16)$ in the gestational age of $30-38$ weeks. A systolic blood pressure $\geq 140 \mathrm{~mm} \mathrm{Hg}$ and/or diastolic blood pressure $\geq 90 \mathrm{~mm} \mathrm{Hg}$ and proteinuria of $\geq 300 \mathrm{mg}$ per 24 hours were used to define PE (10). Only pregnant Black African women aged 18 years and older were included in the study. On the other hand, patients with cardiac disease chronic diabetes and hypertension, abruptio placentae, antiphospholipid antibody syndrome, chronic renal disease, gestational diabetes, connective tissue conditions, sickle cell disorders, chorioamnionitis, polycystic ovarian syndrome, thyroid disorder, un-booked patients, and those incapable of providing informed consent were omitted from the study. Medical records were applied to collect demographic and clinical data.

\section{Quantification of Analytes}

The maternal circulating levels of copeptin (1:2) and fibronectin (1:5) were measured in triplicate using serum samples according to the manufacturer's instructions (Cloud-Clone Corp, TX, USA, Elabscience, USA). The optical density (OD) for all immunoassays were spectrophotometrically determined at a wavelength of $450 \mathrm{~nm}$. The OD values were directly proportional to concentration values for fibronectin but inversely proportional for copeptin.

\section{Data Analysis}

All data were evaluated using STATA (version 12, StataCorp) and presented as medians and interquartile ranges for continuous data and frequency distributions for categorical variables. The Spearman's Chi-square test was used to evaluate bivariate associations between copeptin and fibronectin with demographic and clinical variables. Spearman's correlation was also employed to investigate the association between copeptin and fibronectin. Further, the correlation was used to estimate whether the levels of copeptin and fibronectin relied on maternal epidemiological and clinical characteristics. A $P \leq 0.05$ was considered statistically significant.

\section{Results}

Demographic and Clinical Characteristics

The demographic and clinical profiles are shown in Table
1. The mean age of the normotensive and preeclamptic study groups were 26 and 33 years, respectively, while the mean gestational age was 28 weeks (Table 1). As expected, a statistically significant difference was found in both systolic and diastolic blood pressures between the preeclamptic and the normotensive groups $(P<0.005)$. Contrarily, a downregulation was observed in the concentration of fibronectin in the preeclamptics in comparison to the normotensive group $(P<0.05)$. Copeptin displayed an upward trend in the preeclamptic versus the control group.

Spearman's Correlation Matrix Between Copeptin, Fibronectin, and Clinal Parameters

Table 2 provides the bivariate analysis between the levels of copeptin and fibronectin, and the clinical characteristics of normotensive and preeclamptic groups. A weak, negative correlation was observed between copeptin and fibronectin in both normotensive and preeclamptic groups $(r=-0.15, P>0.05)$. Furthermore, a negative association was found between systolic blood pressure and maternal age $(r=-0.70, P<0.05)$ among the normotensive group. Moreover, both maternal age $(\mathrm{r}=0.59, P<0.05)$ and gestational age $(r=0.52, P<0.05)$ were positively associated with maternal weight among the preeclamptic group. In the preeclamptic group, gestational age was negatively associated with systolic blood pressure $(\mathrm{r}=-0.8, P<0.05)$ whereas a negative association was noted between diastolic blood pressure and maternal weight $(\mathrm{r}=-0.58, P<0.05)$ and gestational age $(\mathrm{r}=-0.76, P<0.05)$. However, a positive correlation was observed between diastolic blood pressure and systolic blood pressure $(\mathrm{r}=0.65, P<0.05)$ among the preeclamptic group.

\section{Discussion}

The main study finding represents the tendency of elevated serum copeptin expression in the preeclamptic compared to normotensive pregnant women. Our results corroborate various other reports regardless of the lack of statistical significance $(1,11,12)$. PE in women is associated with abnormal Doppler velocimetry and elevated copeptin levels, suggestive of either a direct or indirect copeptin effect on endothelial function. The latter group also demonstrated elevated plasma copeptin

Table 1. Demographic and Clinical Characteristics (Median, 25th-75th percentile)

\begin{tabular}{|c|c|c|c|}
\hline & Normotensive $(n=16)$ & Preeclamptic $(n=16)$ & $P$ Value \\
\hline Maternal age (y) & $26.00(21.50-30.50)$ & $33.00(27.00-38.00)$ & 0.06 \\
\hline Maternal weight (kg) & $77.00(71.00-88.00)$ & $78.50(63.50-94.00)$ & 0.92 \\
\hline Gestational age (wk) & $27.50(24.50-72.00)$ & $27.50(25.00-31.50)$ & 0.98 \\
\hline Systolic blood pressure (mm Hg) & $104.00(100.00-116.00)$ & $158.00(152.50-162.50)^{*}$ & $<0.005$ \\
\hline Diastolic blood pressure (mm Hg) & $67.00(60.00-75.00)$ & $104.00(91.00-107.50)^{*}$ & $<0.005$ \\
\hline Fibronectin (ng/mL) & $125.41(111.02-161.30)$ & $39.65(33.95-59.80)^{*}$ & $<0.005$ \\
\hline Copeptin (pg/mL) & $68.22(65.51-76.79)$ & $71.49(63.27-81.94)$ & 0.59 \\
\hline
\end{tabular}

Note. ${ }^{*} P<0.05$ is considered statistically significant. 
Table 2. Spearman's Correlation Between the Clinical Parameters of Normotensive and Preeclamptic Pregnant Women

\begin{tabular}{|c|c|c|c|c|c|c|c|}
\hline & $\begin{array}{l}\text { Fibronectin } \\
(\mathrm{ng} / \mathrm{mL})\end{array}$ & $\begin{array}{l}\text { Copeptin } \\
(\mathrm{pg} / \mathrm{mL})\end{array}$ & $\begin{array}{l}\text { Maternal Age } \\
(y)\end{array}$ & $\begin{array}{c}\text { Maternal } \\
\text { Weight (kg) }\end{array}$ & $\begin{array}{l}\text { Gestational } \\
\text { Age (wk) }\end{array}$ & $\begin{array}{c}\text { Systolic Blood } \\
\text { Pressure }(\mathrm{mm} \mathrm{Hg})\end{array}$ & $\begin{array}{l}\text { Diastolic Blood } \\
\text { Pressure }(\mathrm{mm} \mathrm{Hg})\end{array}$ \\
\hline \multicolumn{8}{|c|}{ Normotensive $(n=16)$} \\
\hline Fibronectin & 1.00 & & & & & & \\
\hline Copeptin (pg/mL) & -0.15 & 1.00 & & & & & \\
\hline Maternal age (y) & 0.45 & -0.14 & 1.00 & & & & \\
\hline Maternal weight (kg) & 0.22 & 0.06 & -0.25 & 1.00 & & & \\
\hline Gestational age (wk) & 0.00 & -0.12 & 0.15 & 0.26 & 1.00 & & \\
\hline Systolic blood pressure (mm Hg) & -0.01 & -0.13 & $-0.70^{*}$ & -0.23 & -0.24 & 1.00 & \\
\hline Diastolic blood pressure $(\mathrm{mm} \mathrm{Hg})$ & -0.01 & -0.34 & 0.48 & -0.05 & 0.17 & 0.46 & 1.00 \\
\hline \multicolumn{8}{|c|}{ Preeclamptic $(n=16)$} \\
\hline Fibronectin & 1.00 & & & & & & \\
\hline Copeptin (pg/mL) & -0.15 & 1.00 & & & & & \\
\hline Maternal age $(y)$ & -0.16 & 0.17 & 1.00 & & & & \\
\hline Maternal weight (kg) & -0.06 & 0.00 & $0.59^{*}$ & 1.00 & & & \\
\hline Gestational age (wk) & -0.04 & -0.21 & 0.39 & $0.52^{*}$ & 1.00 & & \\
\hline Systolic blood pressure (mm Hg) & 0.30 & 0.36 & -0.17 & -0.10 & $-0.80^{*}$ & 1.00 & \\
\hline Diastolic blood pressure $(\mathrm{mm} \mathrm{Hg})$ & 0.45 & 0.08 & -0.39 & $-0.58^{*}$ & $-0.76^{*}$ & $0.65^{*}$ & 1.00 \\
\hline
\end{tabular}

Note. ${ }^{*} P<0.05$ is considered statistically significant.

levels across all three trimesters of PE compared to normotensive pregnancies (12). The increased levels of copeptin may activate vascular endothelial growth factor secretion within the blood vessels (13).

The serum levels of fibronectin in our cohort were significantly downregulated in the preeclamptic versus the normotensive pregnant women. Our findings contradict the upregulation observed by others, which may be attributed to the heterogeneous nature of their preeclamptic population, namely, early and late-onset PE $(14,15)$. We were able to overcome this drawback by limiting our recruitment to women with early onset PE. However, Ajibola's group failed to demonstrate any significant differences in plasma fibronectin levels between $\mathrm{PE}$ and normotensive pregnant women (16). The potential utility of fibronectin as a biomarker for PE prediction received some attention although concerns increased surrounding its sensitivity (17). In one study, Madazli et al reported a cut-off predictive value of $370 \mathrm{mg} / \mathrm{L}$ for mid-trimester serum fibronectin levels as less predictive in identifying those at the risk of PE development when compared to mid-trimester serum PlGF and activin levels (18). Variations in sensitivity may be attributed to the predominance of the total fibronectin as cellular isoforms. A limitation of our study may be associated with the applied fibronectin kit. The sensitivity was probably higher for cellular isoforms instead of soluble fibronectin isoforms, thereby, justifying the downregulation in serum fibronectin observed in our PE cohort.

Interestingly, Foda et al confirmed that vaginal delivery may be associated with higher copeptin levels when compared to elective repeat caesarean sections (11). The elevated levels of copeptin were also observed in women diagnosed with mild PE delivering through normal vaginal delivery in contrast to normotensive vaginal deliveries (11). It is possible that AVP directly induces epinephrine production and cortisol secretion, consequently, conserving the blood volume and elevating blood pressure. Elevated copeptin levels appear to be correlated with PE severity and the stress associated with vaginal delivery, thus stimulating the hypothalamic-pituitary-adrenal axis (11).

As expected, a significant association was also observed for both systolic and diastolic blood pressures between the normal and preeclamptic pregnant women. However, elevations in blood pressure representing hypertension are also reported to confer adaptive mechanisms which improves blood flow in the placental bed (19). Nonetheless, such aberrant elevations must be regulated to avoid a rise in mean arterial pressure above the suggested threshold of $130 \mathrm{~mm} \mathrm{Hg}$, which consequently can increase the risk of stroke (20). Contrarily, we acknowledge the small sample size and late antenatal booking as the limitations of our study, which can affect the early management of antenatal complications. The upregulation and downregulation between biomarkers may be associated with the low sample number in our study, however, it is must be noted that all biomarker data are represented in triplicate.

\section{Conclusions}

To the best of our knowledge, this was the first study to report a dysregulation of serum copeptin and fibronectin in Black pregnant women of African ancestry. At term, serum fibronectin was significantly downregulated in $\mathrm{PE}$ compared to normotensive pregnant women. Thus, serum fibronectin may be a good diagnostic indicator of PE development, however, its predictive value requires further interpretation. Based on the findings, higher 
levels of copeptin were observed in PE as well. This elevation is notably linked to the fact that AVP directly induces epinephrine production and cortisol secretion, consequently, sustaining blood volume and increasing blood pressure. Although this elevation has a predictor test value, it may be important for testing its value detection of the severity of PE and obtaining adverse neonatal outcomes.

\section{Authors' Contribution}

NG, PR and TN designed and conceptualized the study. KD and SR were responsible for the experimental work, data collection and analysis. The first draft was written by NG and all authors commented on this version. All authors read and approved the final manuscript.

\section{Conflict of Interests}

Authors declare that they have no conflict of interests.

\section{Ethical Issues}

This study was approved by the Institutional Research Ethics Committee (IREC 010/17), Durban University of Technology. All participants gave written informed consent.

\section{Financial Support}

This study was supported by the National Research Foundation (UID: 107236) and the South African Medical Research Council (Grant No. DUT/MH1).

\section{Acknowledgments}

The authors appreciate all those who participated in the study.

\section{References}

1. Akinlade KS, Adediji IO, Rahamon SK, Fawole AO, Tongo OO. Serum copeptin and pregnancy outcome in preeclampsia. Niger Med J. 2015;56(5):362-368. doi:10.4103/0300-1652.170385

2. Staff AC. The two-stage placental model of preeclampsia: an update. J Reprod Immunol. 2019;134-135:1-10. doi:10.1016/j. jri.2019.07.004

3. Zeisler H, Llurba E, Chantraine F, et al. Predictive value of the sFlt-1: PIGF ratio in women with suspected preeclampsia. N Engl J Med. 2016;374(1):13-22. doi:10.1056/NEJMoa1414838

4. Levine RJ, Maynard SE, Qian C, et al. Circulating angiogenic factors and the risk of preeclampsia. N Engl J Med. 2004;350(7):672-683. doi:10.1056/NEJMoa031884

5. Cartwright JE, Fraser R, Leslie K, Wallace AE, James JL. Remodelling at the maternal-fetal interface: relevance to human pregnancy disorders. Reproduction. 2010;140(6):803-813. doi:10.1530/rep10-0294

6. Katan M, Morgenthaler N, Widmer I, et al. Copeptin, a stable peptide derived from the vasopressin precursor, correlates with the individual stress level. Neuro Endocrinol Lett. 2008;29(3):341346.

7. Mosher DF. Physiology of fibronectin. Annu Rev Med. 1984;35:561-575. doi:10.1146/annurev.me.35.020184.003021
8. Paarlberg $\mathrm{KM}$, de Jong $\mathrm{CL}$, van Geijn $\mathrm{HP}$, van Kamp GJ, Heinen AG, Dekker GA. Total plasma fibronectin as a marker of pregnancy-induced hypertensive disorders: a longitudinal study. Obstet Gynecol. 1998;91(3):383-388. doi:10.1016/s00297844(97)00683-2

9. Birdir C, Janssen K, Stanescu AD, et al. Maternal serum copeptin, MR-proANP and procalcitonin levels at 11-13 weeks gestation in the prediction of preeclampsia. Arch Gynecol Obstet. 2015;292(5):1033-1042. doi:10.1007/s00404-015-3745-7

10. Brown MA, Magee LA, Kenny LC, et al. Hypertensive disorders of pregnancy: ISSHP classification, diagnosis, and management recommendations for international practice. Hypertension. 2018;72(1):24-43. doi:10.1161/hypertensionaha.117.10803

11. Foda AA, Abdel Aal IA. Maternal and neonatal copeptin levels at cesarean section and vaginal delivery. Eur J Obstet Gynecol Reprod Biol. 2012;165(2):215-218. doi:10.1016/j.ejogrb.2012.08.012

12. Santillan MK, Santillan DA, Scroggins SM, et al. Vasopressin in preeclampsia: a novel very early human pregnancy biomarker and clinically relevant mouse model. Hypertension. 2014;64(4):852859. doi:10.1161/hypertensionaha.114.03848

13. Tahara A, Tsukada J, Tomura Y, Yatsu T, Shibasaki M. Vasopressin induces human mesangial cell growth via induction of vascular endothelial growth factor secretion. Neuropeptides. 2011;45(2):105-111. doi:10.1016/j.npep.2010.12.001

14. Friedman SA, de Groot CJ, Taylor RN, Golditch BD, Roberts JM. Plasma cellular fibronectin as a measure of endothelial involvement in preeclampsia and intrauterine growth retardation. Am J Obstet Gynecol. 1994;170(3):838-841. doi:10.1016/s00029378(94)70295-0

15. Uzun H, Konukoglu D, Albayrak M, et al. Increased maternal serum and cord blood fibronectin concentrations in preeclampsia are associated with higher placental hyaluronic acid and hydroxyproline content. Hypertens Pregnancy. 2010;29(2):153162. doi:10.3109/10641950902968619

16. Ajibola SO, Adeyemo TA, Afolabi BB, Akanmu AS. Utility of a single mid-trimester measurement of plasminogen activator type 1 and fibronectin to predict preeclampsia in pregnancy. Niger Med J. 2016;57(4):213-216. doi:10.4103/0300-1652.188337

17. Dreyfus M, Baldauf JJ, Ritter J, Van Cauwenberg JR, Hardy A, Foidart JM. The prediction of preeclampsia: reassessment of clinical value of increased plasma levels of fibronectin. Eur J Obstet Gynecol Reprod Biol. 1998;78(1):25-28. doi:10.1016/ s0301-2115(98)00015-3

18. Madazli R, Kuseyrioglu B, Uzun H, Uludag S, Ocak V. Prediction of preeclampsia with maternal mid-trimester placental growth factor, activin A, fibronectin and uterine artery Doppler velocimetry. Int J Gynaecol Obstet. 2005;89(3):251-257. doi:10.1016/j. ijgo.2005.02.008

19. Ngene NC, Moodley J. Physiology of blood pressure relevant to managing hypertension in pregnancy. J Matern Fetal Neonatal Med. 2019;32(8):1368-1377. doi:10.1080/14767058.2017.1404 569

20. Varkaris A, Katsiampoura A, Kelliher T, Huang CC. Update in the management of cerebrovascular accidents. Hosp Med Clin. 2017;6(2):176-192. doi:10.1016/j.ehmc.2016.11.003

(C) 2021 The Author(s); This is an open-access article distributed under the terms of the Creative Commons Attribution License (http:// creativecommons.org/licenses/by/4.0), which permits unrestricted use, distribution, and reproduction in any medium, provided the original work is properly cited. 